\title{
Multi-index Economical Peak Load Regulation Model Based on Improved Particle Swarm Optimization
}

\author{
Xiaohong Hao 1, a, Jingyuan Yang 2,b \\ ${ }^{1}$ School of Computer \& Communication, Lanzhou University of Technology, Lanzhou 730050,China \\ ${ }^{2}$ College of Electrical and information Engineering, Lanzhou University of Technology, Lanzhou \\ 730050,China \\ ahaoxhlut@163.com, b254214095@qq.om,
}

\begin{abstract}
Keywords: virtual power plant; multi-objective optimization; peak load regulation; Grey Particle Swarm Optimization

Abstract. In recent years, new energy continued rapid growth in China. Installed capacity of wind power and solar power both surged the new highs. However, the problem of insufficient peak peaking capacity of power system of large-scale new energy grid becoming more and more serious due to the random and intermittent characteristics of wind power and photovoltaic. This paper put forward a strategy of virtual power plant, which consisting of uncontrollable renewable energy and controllable energy will participate peak load regulation. With goal of minimizing the load variance and operating cost in each period, a multi-objective peak load regulation modes of virtual power plant is established. Power output of each energy resource of virtual power plant is obtained with improved grey particle swarm algorithm. Take the IEEE33 node distribution system as an example to simulate. The results show that the peak load regulation model can be carried out economically and effectively peak-shaving.
\end{abstract}

\section{Introduction}

Nowadays, the new energy with the green, flexible and economical advantages have been vigorously developed and widely used. However, such as wind power and photovoltaic distributed generation (DG) output has the randomness and intermittent, which has brought great challenges for the power system of peaking scheduling. Aiming at the new energy large-scale accessing the power grid, the traditional solution is optimizing the unit to complete the peaking task. In [2-3], the peak model of wind power grid integration, according to the power structure and load characteristics, is the established. But these methods do not take into account the adjustable resources in the load side. In [4-5], it proposed the use of interruptible load as a peak load on the power grid scheduling. In [6-7], it proposed the use of large-scale energy storage system unit on the power grid load to reduce the system load fluctuations in this flat power unit output, so that the power grid with more capacity to absorb wind power. In this study, different types of distributed energy resources (DER) are involved in the research of the power system peak-shunting scheduling model. But the DER type is considered to be single.

Therefore, this paper uses the virtual power plant (VPP) as a running strategy to manage the different types of DERs, wind power generation and photovoltaic power generation and then construct a multi-target peak-shunting scheduling model and optimize the virtual power plant DER output to achieve the purpose of economic peaking by improving the gray PSO algorithm.

\section{Peak Load Regulation Modes based on Virtual Power Plant}

Virtual power plant market rules include two aspects: On the one hand, the rules of the market between the VPP and distribution companies: VPP and the electricity market establish time-of-use price link. When the VPP can not meet the need of load, it could purchase electricity from the super power grid at the time-of-use price. On the other hand, the rules of the market between the VPP and users: VPP and the Users establish time-of-use price link. VPP dispatch own unit of distributed energy resources or buys power for the load and VPP sell the electricity to the users at a fixed retail 
price. The frame structure includes non-schedulable DG (wind power and photovoltaic power generation), schedulable DG (fuel cell FC and micro-gas turbine MT), energy storage unit and interruptible load. VPP manage DG and various types of DER. Distribution companies do not participate in VPP's internal energy management and only need to provide power to the VPP.

\section{Multi-objective Optimization Scheduling of Peak Load Regulation Modes based on Virtual} Power Plant

Objective Function: This method will be able to interrupt the load and energy storage unit as a peak-shaving means and establish the peak shaving model as the goal of minimizing the load variance and operating costs in each period. The minimizing the load variance is:

$$
\begin{aligned}
& \min \mathrm{D}=\frac{1}{\mathrm{n}} \sum_{\mathrm{i}=1}^{\mathrm{n}}\left(P_{L}-P_{V P P}\right)^{2} . \\
& P_{V P P}=P_{w t}+P_{p v}+P_{D G}+P_{o m}+P_{R L}-P_{\text {loss. }} .
\end{aligned}
$$

Where $\mathrm{n}$ is the number of hours in the scheduling period; $P_{L}$ is the load; $P_{V P P}$ is the power of DG and DER the VPP manage. The minimizing operating costs in each period is:

$$
\begin{aligned}
& \operatorname{minf}=\sum_{\mathrm{i}=1}^{\mathrm{n}} C_{D G}+C_{o m}+C_{R L}+C_{\text {grid }} . \\
& C_{D G}=\sum_{j \in G} C_{D G} \cdot \Delta \mathrm{t} \cdot\left(P_{F C}+P_{M T}\right) . \\
& C_{o m}=\sum_{k \in S} C_{o m} \cdot \Delta \mathrm{t} \cdot\left|P_{o m}\right| . \\
& C_{R L}=\sum_{v E} c_{R L} \cdot \Delta \mathrm{t} \cdot P_{R L} . \\
& C_{\text {grid }}=\sum_{v E} C_{\text {gria }} \cdot \Delta \mathrm{t} \cdot P_{\text {grid }} .
\end{aligned}
$$

Where $C_{D G}$ is the cost to purchase from DG; $C_{o m}$ is the cost to maintain the energy storage unit; $C_{R L}$ is the cost of RL; $C_{\text {grid }}$ is the cost to purchase from the super grid; $C_{\text {grid }}$ is time-of-use price.

Constraint Condition: The constraint of grid balance is:

$$
P_{\text {grid }}+\sum_{\mathrm{j} \in \mathrm{N}} P_{D G}+\Sigma_{\mathrm{u} \in \mathrm{P}} P_{D G}+\sum_{\mathrm{weC}} P_{\mathrm{RL}}+\Sigma_{\mathrm{KeS}} P_{\mathrm{om}}-P_{L}-P_{\text {loss }}=0
$$

Where $\mathrm{N}$ is the unit of controllable DG (FC and MT); P is the unit of uncontrollable DG (wind power and Photovoltaic system)

The power flow constraints is:

$$
\begin{aligned}
& \mathrm{P}_{\mathrm{i}}=\mathrm{U}_{\mathrm{i}} \sum_{\mathrm{j}=1}^{\mathrm{n}} \mathrm{U}_{\mathrm{j}}\left(\mathrm{G}_{\mathrm{ij}} \cos \delta_{\mathrm{ij}}+\mathrm{B}_{\mathrm{ij}} \sin \delta_{\mathrm{ij}}\right) . \\
& \mathrm{Q}_{\mathrm{i}}=\mathrm{U}_{\mathrm{i}} \sum_{\mathrm{j}=1}^{\mathrm{n}} \mathrm{U}_{\mathrm{j}}\left(\mathrm{G}_{\mathrm{ij}} \sin \delta_{\mathrm{ij}}-\mathrm{B}_{\mathrm{ij}} \cos \delta_{\mathrm{ij}}\right) .
\end{aligned}
$$

Where $n$ is the number of system nodes; $G_{\mathrm{ij}} 、 \mathrm{~B}_{\mathrm{ij}} 、 \delta_{\mathrm{ij}}$ respectively is admittance and angular phase difference.

The controllable energy constraints is:

$$
\mathrm{R}_{\mathbb{N}_{\mathrm{j} j \mathrm{j}} \mathrm{Tin}}^{\mathrm{T}} \leq \mathrm{R}_{\mathrm{N}, \mathrm{j}}^{\mathrm{T}} \leq \mathrm{R}_{\mathrm{N}, \mathrm{j}, \mathrm{max}}^{\mathrm{T}} \text {. }
$$

The energy storage unit constraints is:

$$
\mathrm{P}_{\text {om } \operatorname{smin}}^{\mathrm{T}} \leq \mathrm{P}_{0 \mathrm{~m} \cdot s}^{\mathrm{T}} \leq \mathrm{P}_{\text {om } \mathrm{s} \cdot \mathrm{max}}^{\mathrm{T}} \text {. }
$$

The load demand response users could reduce constraints is:

$$
\mathrm{P}_{\mathrm{RL} \text { wmin }}^{\mathrm{T}} \leq \mathrm{P}_{\mathrm{R} L w}^{\mathrm{T}} \leq \mathrm{P}_{\mathrm{R} L w \max }^{\mathrm{T}} \text {. }
$$

\section{Model solution}

Improved Particle Swarm Optimization: Particle swarm optimization algorithm is an intelligent algorithm. The algorithm simulates the behavior birds feed, which rely on the collective cooperation between birds to achieve the best. Its principle is simple. In Mathematics, the particle position and velocity generally expressed as:

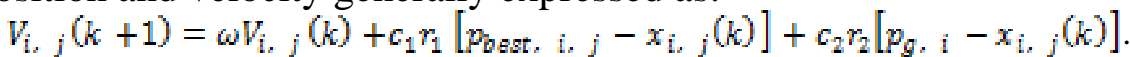

$$
\begin{aligned}
& x_{i, j}(k+1)=x_{i, j}(k)+V_{i, j}(k+1), j=1,2, \ldots, d \text {. }
\end{aligned}
$$

Where $\mathrm{K}$ represents the $\mathrm{k}$ times iterate; is learning factor; is random numbers between $[0,1]$; is inertia weight; is personal best; is optimal solution; $i$ is particle dimension; $j$ is particle number; 、 respectively is the position the particle $\mathrm{j}$ iterated in $\mathrm{k}$ times and in $\mathrm{k}+1$ times.

In the adjustable parameters of particle swarm, is the most important parameters. The larger is helpful to improve the global searching ability of the algorithm and the smaller can enhance the local search ability of the algorithm. In this paper, the nonlinear dynamic inertia weight coefficient formula is used to improve the basic PSO particle swarm optimization algorithm to balance ability between global searching ability and local search ability 


$$
\left\{\begin{array}{c}
\omega_{\min }-\frac{\left(\omega_{\max }-\omega_{\min }\right)-\left(f-f_{\min }\right)}{f_{\text {avg }}}, f>f_{\text {avg }} \\
\omega_{\max }, f \leq f_{\text {avg }} .
\end{array}\right.
$$

Where ${ }^{\omega} \min$ 、 $\omega_{\max }$ respectively is maximum and minimum of ${ }^{\omega} . f$ is current objective function value. In the above equation, the inertia weight ${ }^{\omega}$ is automatically adjusted with the objective function value of the particle.

Multi-objective Particle Swarm Optimization Based on Gray Relational Degree. In the power system, internal variables is complex. During the solutions, it is impossible for each objective function to make multiple target values optimal due to that each objective function is conflicting. The optimal solution of a multiobjective function is a set of solutions that can not be further optimized without any other objective function under the condition that the objective function is not degraded, which is Pareto optimal solution set. During the actual operation of the grid, the dispatchers must choose the optimal scheme from a set of Pareto optimal solutions. This method is complex operation for the dispatchers. It could not quickly response in real-time peak dispatch process and the optimization results lack of objectivity and persuasion with the subjectivity of the operator. This paper proposes a multiobjective particle swarm optimization algorithm based on gray relational degree.

Set reference vector sequence $x_{j}=\left\{\left\langle\left. x_{0}(k)\right|_{k}=1,2, \ldots, n\right)\right\}$, target vector sequence $^{X_{j}}=\left\{\left(x_{j}(k) \mid j=1,2, \ldots, m\right)\right\}$.

Where $\mathrm{k}$ is the target vector sequence; $\mathrm{j}$ is serial number.

The grey correlation coefficient between $X_{j}$ and $X_{0}$ is:

$\varepsilon_{k}=\frac{\operatorname{minmin}\left|x_{0}(k)-x_{j}(k) \|+\zeta \operatorname{minmin}\right| x_{0}(k)-x(k) \mid}{\| x_{0}(k)-x_{j}(k)|+\zeta \operatorname{maxmax}| x_{0}(k)-x_{j}(k) \mid}$.

The gray correlation is:

$\mathrm{Y}=\frac{1}{n} \sum_{k=1}^{n} \varepsilon_{k}$.

Where $\zeta$ is resolution factor, which is pre-determined constant $\zeta$ usually is 0.5 .

The algorithm flow chart shown in Fig. 1: 


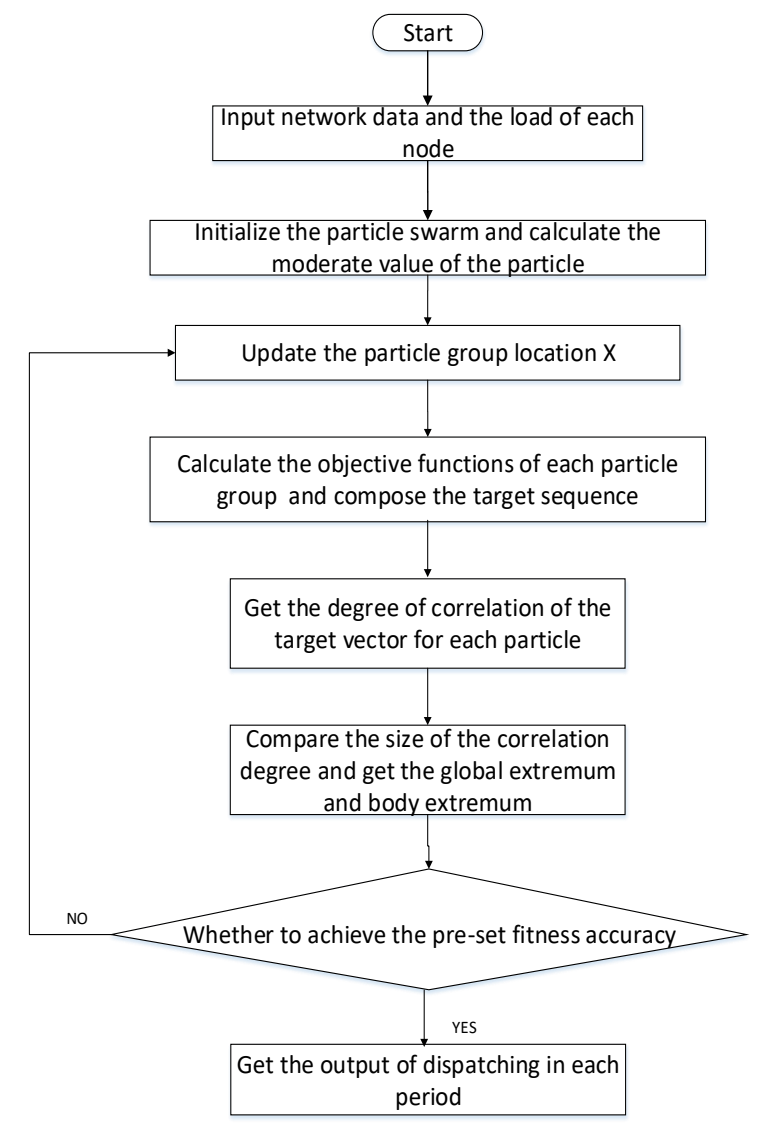

Fig.1 Flow chart of algorithm

\section{Simulation results analysis}

An example description. In this paper, the improved IEEE33 node distribution system is applied for simulation verification. The system wiring diagram is shown in Fig. 2. The system installs fuel cells at nodes 7、15, installs Micro gas turbine at nodes 17、20、28 installs interruptible load at nodes 25、32 and installs energy storage unit at nodes 24 . The system installs wind power and photovoltaic power generation at nodes $7 、 30$, which is uncontrollable energy. The intermittent renewable energy is used to predict the output power. The output power is shown in Fig.3. The 24-day load forecast curve is shown in Fig. 4.

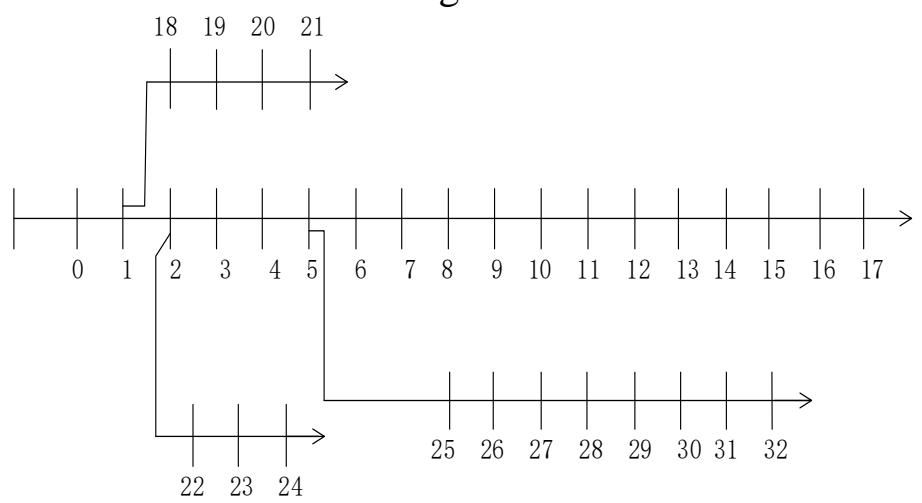

Fig.2. IEEE33 node distribution system 


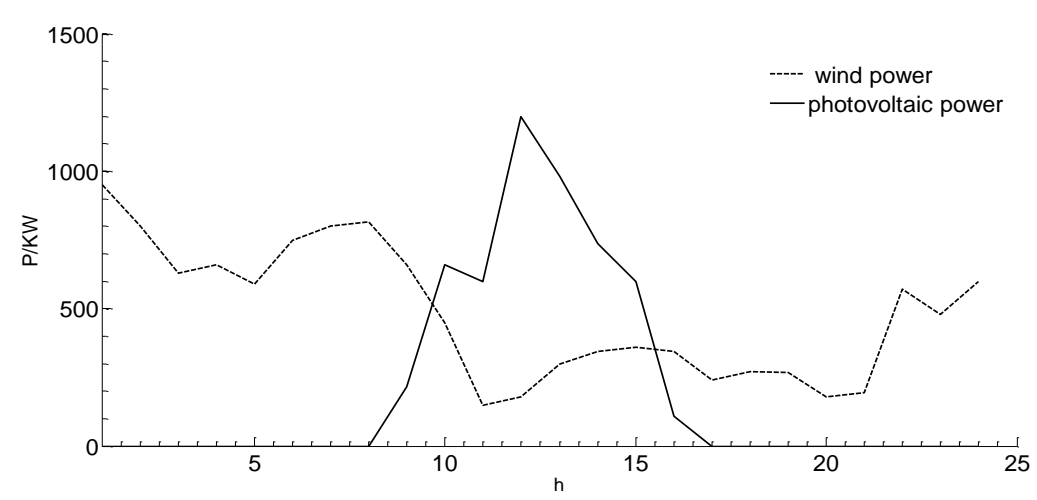

Fig.3. Wind power and photovoltaic power generation

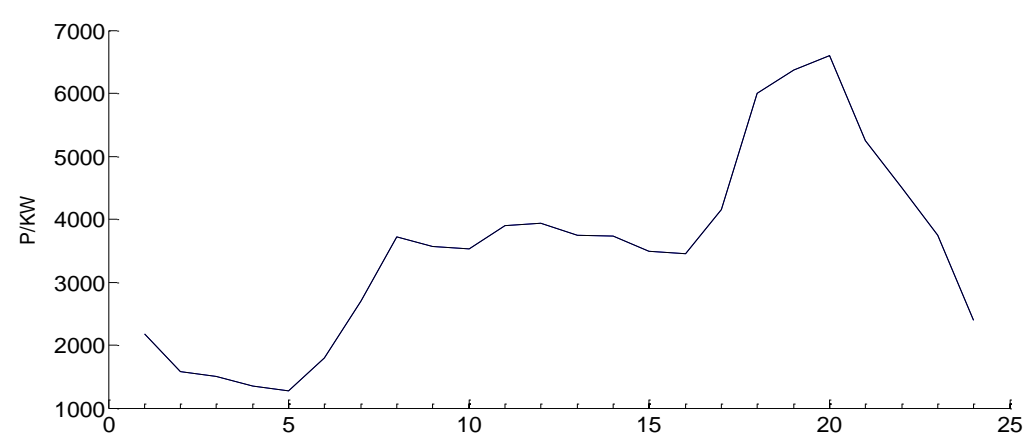

Fig.4. The 24-day load forecast curve

In this paper, according to the situation of each DER participating in the peak regulation of the power grid, three kinds of peaking dispatching methods are divided from three aspects: load variance, grid operating cost and net loss to verify the feasibility of the proposed peak shaving model. The simulation results are shown in Table.1. As can be seen from the table, fully DG load running is the way to effectively reduce the load variance, but its cost is huge, which does not have the economy. Only DG participates peaking is also commonly used in the traditional way of peak peaking, that is, through the FC and MT to respond to the load demand. The output of DG is reduced during peak peaking due to the high cost of purchasing electricity to DG and through the way to purchase power from the super power grid to meet the needs of the load. This paper proposed the methods that the energy storage unit and interruptible load both participate in the peak regulation not only is greater extent to reduce load variance, but also reduce the cost of grid operation compared to traditional peak shaving methods. Energy storage unit discharge is equivalent to access to power. While the interruptible load could reduce part of the load demand, which greatly reduce the power grid network loss and further improve the power grid peaked economy.

Table.1. Statics results of three kinds of peaking modes

\begin{tabular}{|c|c|c|c|}
\hline Peaking mode & Load variance & $\begin{array}{c}\text { Grid operating } \\
\text { costs }\end{array}$ & Loss of power grid \\
\hline $\begin{array}{c}\text { fully load of DG } \\
\text { runnning }\end{array}$ & 1024 & 50091.8 & 2334 \\
\hline $\begin{array}{c}\text { only DG } \\
\text { participates } \\
\text { peaking }\end{array}$ & 2119 & 40748.3 & 2950 \\
\hline $\begin{array}{c}\text { All DERs } \\
\text { participates } \\
\text { peaking }\end{array}$ & 1972 & 38486.7 & 2510 \\
\hline
\end{tabular}

\section{Conclusions}

In this paper, Multi-objective optimization scheduling method considering the new energy access grid and taking into account the network loss is established, which using the wind, solar energy, 
storage and control DG to participate in the peak of the scheduling. The particle swarm optimization algorithm on the basis of gray relational degree theory is used to solve multi - objective optimization problem. The simulation results show that the proposed peak-shaving model can reduce the grid operation cost and reduce the network loss, and make the system more economical and stable operation, compared with the traditional peak-proofing method.

\section{References}

[1] Zhinong Wei, Shuang Yu, Guoqiang Sun, et al. Concept and development of virtual power plant [J]. Automation of Electric Power Systems, 2013, 37(3): 1-6. (In Chinese)

[2] Rongfu Sun, Tao Zhang, Ji Liang. Evaluation and application of acceptance of wind power in power grid [J]. Automation of Electric Power Systems, 2011, 04:70-76. (In Chinese)

[3] Tingting Hou, Suhua Lou, Yaowu Wu, et al. Analysis on peak load regulation operation characteristics of power system integrated with large-scale wind power [J]. TRANSACTIONS OF CHINA ELECTROTECHNICAL SOCIETY, 2013, 28(5):105-111. (In Chinese)

[4] Cong Liu, Wenying Liu, Weizhou Wang, et al. A quantitative method to pre-evaluate power grid's capability of accommodation for wind/photovoltaic power under participation of high-energy load. [J]. Power System Technology, 2015, 01:223-229. (In Chinese)

[5] Gangui Yan, Xiaodong Feng. Optimization of energy storage system capacity for relaxing peak load regulation bottlenecks [J]. Proceedings of the CSEE, 2012, 32(28):27-35. (In Chinese)

[6] Tao Yan, Zhanzhan Qu, Dong Hui, et al. Economic Analysis of Commercial Virtual Power Plant with Large Scale Battery Energy Storage System [J]. Automation of Electric Power Systems, 2014, 38(17):98-103. (In Chinese)

[7] Wenying Liu, Jing Wen, Chang Xie, et al. Multi-objective optimal method considering wind power accommodation based on source-load coordination [J]. Proceedings of the CSEE, 2015, 35(5):1079-1088. (In Chinese)

[8] Nan Yang, Bo Wang, Dichen Liu, et al. Large-Scale wind power stochastic optimization scheduling method considering flexible load peaking [J]. TRANSACTIONS OF CHINA ELECTROTECHNICAL SOCIETY, 2013, 28(11):231-238. (In Chinese) 